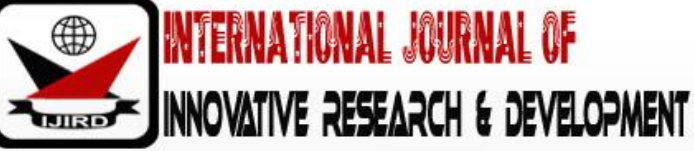

ISSN 2278 - 0211 (Online)

\section{Health Services Related Factors Influencing Utilization of Antenatal Care (ANC) Services among Expectant Women in Turkana County, Kenya}

\author{
Jane Auru Ajele \\ Executive Committee Member, Ministry of Health, Turkana County Government, Kenya \\ Dr. Jackline Mosinya Nyaberi \\ Lecturer, School of Public Health, Jomo Kenyatta University of Agriculture and Technology, Kenya \\ Dr. Catherine Gichunge \\ Lecturer, School of Science, Turkana University College, Kenya
}

\begin{abstract}
:
Antenatal Care (ANC) is a strategic intervention for promoting safe motherhood and reducing maternal mortality and morbidity. A woman dies every minute due to pregnancy-related complications whereas developing countries account for $99 \%$ of the global maternal deaths. Low utilization of antenatal care services remains a key indicator of maternal mortality and morbidity in some parts of Kenya like Turkana County where the geographical terrain is complex as well other social and cultural implications that pose significant risks to pregnant women. The purpose of the study was to assess health servicerelated factors influencing the utilization antenatal care (ANC) services among expectant women in Turkana County, Kenya. The study was carried out in Lodwar County Referral Hospital (LCRH) among pregnant women attending ANC clinic at LCRH and nurses working in the Maternal and Child Health department. Structured questionnaires were used to collect quantitative data involving 297 women and selected using simple random sampling while qualitative data involving 3 nurses working in maternal and child health department was selected purposively and collected using in-depth interviews. Majority of the respondents (48\%) were aged 25-35 years, were married (73\%), Christians (83\%), and had primary education (51\%). Quality of services was significantly associated with the utilization of antenatal care services $(\chi 2=12.950 ; \mathrm{df}=6 ; \mathrm{p}=0.044 *)$. There was no significant association between ANC utilization and the means of transport to seek ANC services $(\chi 2=3.411$; $d f=4 ; p=0.179)$ and where $A N C$ services are accessed $(\chi 2=1.590 ; d f=4 ; p=0.452)$. Women's attitude towards the ANC services and good communication between the health staff and clients also influence women to seek antenatal services. The study recommends the need to train health workers providing antenatal care services not only on clinical skills but also on clientprovider interaction in order to ensure quality and professional delivery of ANC services.
\end{abstract}

Keywords: Health services related factors, antenatal care and utilization

\section{Background}

The health of women is a key indicator of the general health of a country. Antenatal Care (ANC) is one of the four strategic interventions for promoting safe motherhood alongside safe delivery, family planning, and emergency obstetric care. World Health Organization (WHO) (2014) recommends a minimum of four ANC visits initiated during the first trimester of pregnancy. Regular antenatal care visits by pregnant women is valuable in identifying and preventing adverse pregnancy-related outcomes especially when done during early stages of pregnancy and continued throughout the gestation period. The maternal mortality is high in many countries to a point that a woman dies every minute due to pregnancy-related complications. Developing countries account for $99 \%$ of the global maternal deaths with sub-Saharan African region alone accounting for $62 \%$ (WHO, 2014b). Antenatal care allows for the management of pregnancy, detection and treatment of complications and promotion of good health (Bustreo, et al., 2013). The frequency and timing of antenatal care visits are important because they offer the service providers opportunities to identify and address potential pregnancy complications as early as possible African Population and Health Research Centre (APHRC) (2014). In Kenya, the government recommends that pregnant mothers make at least four antenatal care visits during pregnancy, with the first visit occurring early in the pregnancy. For mothers making more than the minimum visits, monthly visits are recommended with the frequency increasing during the last two months of pregnancy to fortnightly and weekly visits.

Maternal morbidity and mortality can be significantly reduced by improving access to ANC services. In spite of the clear benefits of ANC, low utilization of such services remains a key indicator of maternal mortality and morbidity in some parts of Kenya. Recent data from the Kenya Demographic and Health Survey (KDHS) (2016) indicate that some counties like Garissa, Marsabit, West Pokot, Samburu, and Turkana had low number of women receiving ANC services from skilled 
health providers compared to other counties. Worryingly, the KDHS survey revealed significant disparities in the utilization of ANC services across the country. Women in urban settings had a $96 \%$ average rate of receiving care from a skilled provider compared to $94 \%$ of women in rural areas (KDHS, 2016).

To ensure women accesses quality care adequate number of trained health workers, sufficient equipment and supplies; and adequate referral or reliable transportation to a hospital or other health facilities in the event of an emergency (Chorongo, 2016) Studies clearly indicate that countries with high maternal, perinatal and neonatal mortality have inadequate and poor quality health service, which can be associated with reduced utilization of health service. Reference on these studies show that the use of evidence-based guidelines leads to better process and outcomes of health, when appropriately implemented. Emphasis is therefore placed on the use of standards of care as a way of addressing barriers to quality care. Access to ANC is necessary in modifying women's risk behaviours and promoting positive health practices for women. Antenatal care services should be accessible to all pregnant women irrespective of age, social status or level of education and HIV status, and should offer an environment of confidentiality and trust (Bayu, Adefris, Amano, \& Abuhay, 2015). Physical accessibility of services is the most important variable associated with utilization of ANC (Tsegay, Gebrehiwot \& Goicolea, 2013).

Pregnant women would be motivated to use the ANC services if they are acceptable and need focused. Pregnant women expect care that is acceptable and focuses on their individual needs. Pregnant women should be able to access ANC services without any restrictions (Kawungezi et al., 2015). In Ghana, ANC is provided at every health centre/ hospital and it is clear that its availability is acceptable to pregnant women. Since most maternal deaths occur due to preventable obstetric complications, most could be prevented if women had access to high-quality antenatal care, skilled assistance at delivery, and postnatal care Kondwani, Adamson \& Stone, 2017). Majority of pregnant women might not be able to afford the maternity fees chargeable due to financial limitations. Perceived quality of care, which only partly overlaps with medical quality of care, is thought to be an important influence on health-seeking behaviour (Kondwani, Adamson \& Stone, 2017; Gathuto, 2015). Assessment of quality of services depends largely on a person's own experiences with the health system and those of people they know. Although certain elements like waiting times can be measured objectively, the perceptions about the health system are more subjective (Gathuto, 2015).

Turkana County lies in the remote north western region of Kenya, which is mainly inhabited by nomadic pastoralists. The vastness of the County, nomadic pastoral mode of life, inadequacy of health facilities, persistent cattle rustling associated with insecurity and inadequacy of health personnel among other factors pose a myriad of challenges to the delivery of antenatal care services in the County. Besides, some attitudes and practices contribute negatively to maternal health indicators in the County. There was need to understand why the ANC services are not being fully utilized by expectant women in Turkana County despite being aware of their benefits to the mother and the unborn child. This study sought to establish the health service-related factors influencing the utilization antenatal care (ANC) services among expectant women in Turkana County.

\section{Materials and Methods}

A cross-sectional mixed method design study was used to collect data among expectant women seeking antenatal care services at the Lodwar County Referral Hospital (LCRH). For qualitative data the study targeted health service providers, particularly nurses working in the Maternal and Child Health $(\mathrm{MCH})$ department in the hospital. Simple random sampling technique was used to obtain quantitative data from a sample of 297 expectant women. Data was collected using questionnaires and in-depth interviews. Quantitative analysis was analysed using Statistical Package for Social Sciences (SPSS) 20.0. Chi-square $(\chi 2)$ test was used to examine the association existing between various characteristics of expectant women on utilization of antenatal care services.

Qualitative data was analysed by examining relevant themes as per the research questions. Ethical clearance was sought from Mount Kenya University Ethical Review Committee (ERC) (MKU/ ERC/ 0636). Respondents were assured of confidentiality and no names were used or indicated on the questionnaires and respondents signed a written informed consent.

\section{Results}

\subsection{Social Demographic Factors}

The results of socio-demographic characteristics indicate that $48 \%$ of the respondents were aged 25 - 35 years, $28 \%$ ) were aged $15-25$ years, $19 \%$ were aged $35-45$ years whereas only $5 \%$ were aged over 45 years. Majority representing $73 \%$ were married, $8 \%(\mathrm{~N}=21)$ were single while the remaining were in other forms of unions. $24 \%$ had no formal education, $27 \%$ had attained primary education level, forty-five had secondary education, $24 \%$ had college education level while $10 \%$ had university level education and above. An overwhelming majority (83\%) were Christians, $12 \%$ were Muslims while only 5\% belonged to other religious groups. The results are indicated in Table 1.

\subsection{Health Service Provider Factors Influencing ANC Utilization}

The findings as shown in Table 2 indicate that $87 \%$ sought ANC services from government health facilities, twenty-nine (10\%) sought from private clinics while twelve (3\%) sought the services from traditional birth attendants. One hundred and sixty-three (56\%) walked to seek ANC services, ninety (30\%) used public transport, while $14 \%$ used private means of transport. In terms of the respondents' views on quality of services, $1 \%$ of the respondents reported that services were very poor, $2 \%$ reported they were poor, $12 \%$ reported they were average, $70 \%$ said the quality of services was good while $15 \%$ reported the services were of very good quality. 


\subsection{Association between Independent Variables and ANC Utilization}

The study established that quality of ANC service was significantly associated with utilization of ANC services $(\chi 2=12.950 ; \mathrm{df}=6 ; \mathrm{p}=0.04)$. The study did not establish a significant relationship between the utilization of antenatal care services and the means of transport to seek ANC services $(\chi 2=3.411 ; \mathrm{df}=4 ; \mathrm{P}=0.179)$ and where ANC services are accessed $(\chi 2=1.590 ; \mathrm{df}=4 ; \mathrm{P}=0.452)$. The results are indicated in Table 3 .

The above findings were supported by the qualitative interviews from health workers. Most of the respondents emphasized that transport costs and long distances to the clinic make it difficult for many women to seek the available ANC services, opting for TBAs. As one health worker reported; "most women go to the clinic by foot as they cannot afford to take a boda boda which is usually more than Kshs 200 to the nearest health facility" (Key Informant 1). It was also established that perceived costs of the ANC hinder women from attending clinics. As one respondent reported; "most women always complain of being poor and that their finances were in the custody of their spouses while those who are widowed say that they do not have control of the property left to them by their spouse" (Key Informant 2).

Good communication between the health staff and clients was reported as a major factor that influences women to go for antenatal services. The attitude of the general population concerning ANC services was also cited as a contributing factor to the health seeking behaviour of women in need of ANC services. As one respondent indicated, "Some women have the false belief that nurses harass and insult them" (Key Informant 3). Other factors that were mentioned include accessibility of the ANC services to the mothers, availability of skilled personnel at the clinics and availability of other services related to ANC e.g. HIV testing and counseling, laboratory services.

\section{Discussion and Conclusion}

The study determined that the following facility related factors mentioned by pregnant mothers did not influence utilization of ANC services, means of transport to the facility and where ANC services are sought from whereas quality of services influenced the utilization of the ANC services. Findings of this study concur with those of Ministry of HealthKenya, (2010), which assert that quality of care can be measured from the perspectives of clients or providers (perceived quality) or by measuring adherence levels to the set standards and guidelines. The distance to health facility corresponded with study carried out in Siaya county, Kenya which revealed mothers who travel less than one hour had seven times more likely to have early ANC initiation and five times more likely to have at least 4 ANC visits than mothers who travel more than one hour (Asweto, Aluoch, Obonyo \& Ouma, 2014

Factors relating to healthcare providers affecting prenatal care include access to care services and methods of communication. Accessibility-related factors include long distance from the health care facilities offering ANC services, means of transport, booking of clinic appointments, duration of stay and discrimination by antenatal care providers Bhagwan, Kumar, Rao \& Kamath, 2016). Methods of initiating communication between antenatal care givers and pregnant women are among important factors affecting the use of the services (Haver et al., 2015).

The study found a significant association between quality of ANC service and utilization of ANC services. Poor quality of care and negative attitudes of healthcare providers hinders the use of antenatal services (Hagey, Rulisa and Perez-Escamilla, 2014). Besides, poor communication between clients and the healthcare providers, unfriendly behaviours, and negative attitude of healthcare workers are among major factors which inhibit women from receiving proper ANC services as cited in previous studies (Fagbamigbe and Idemudia, 2015). This implies that continuity of antenatal care is determined by the quality of services offered, which is influenced by women's confidence in the healthcare system (Haver et al., 2015; Hagey, Rulisa and Perez-Escamilla, 2014).

The study recommends the need to train health workers especially those providing antenatal care services not only on clinical skills but also on client-provider interaction in order to ensure quality and professional delivery of ANC services. Health workers should be encouraged to provide health education to mothers seeking various health services on the importance of attending ANC clinic in order to improve utilization of ANC services especially in poor settings.

\section{Acknowledgments}

We thank the Director/Chief Executive Officer, Lodwar County Referral Hospital for granting permission to undertake the study in the facility. Special gratitude is also extended to the study participants and the key informants for their cooperation. 


\begin{tabular}{|c|c|c|}
\hline Demographic Variable & Frequency (N) & Percentage (\%) \\
\hline Age Group (years) & & \\
\hline $15-25$ years & 85 & $28 \%$ \\
\hline 25 - 35 years & 140 & $48 \%$ \\
\hline $35-45$ years & 54 & $19 \%$ \\
\hline 45 and above & 14 & $5 \%$ \\
\hline Marital status & & \\
\hline Married & 214 & $73 \%$ \\
\hline Single & 21 & $8 \%$ \\
\hline Divorced/ widowed & 25 & $9 \%$ \\
\hline Other & 33 & $10 \%$ \\
\hline Educational level & & $24 \%$ \\
\hline Not attended school & 70 & $27 \%$ \\
\hline Primary & 77 & $15 \%$ \\
\hline Secondary & 45 & $24 \%$ \\
\hline College & 71 & $10 \%$ \\
\hline University and above & 30 & $83 \%$ \\
\hline Religion & & $12 \%$ \\
\hline Christian & 244 & $5 \%$ \\
\hline Muslim & 33 & \\
\hline Other & 16 & \\
\hline Tabl Soco-Degrap & \\
\hline
\end{tabular}

Table 1: Socio-Demographic Characteristics of Respondents

\begin{tabular}{|c|c|c|c|}
\hline Variable & & Frequency (N) & Percentage (\%) \\
\hline \multirow{3}{*}{$\begin{array}{l}\text { Where ANC services are } \\
\text { accessed }\end{array}$} & Government facilities & 250 & $87 \%$ \\
\hline & Private clinics & 29 & $10 \%$ \\
\hline & Traditional birth attendant & 12 & $3 \%$ \\
\hline \multirow{3}{*}{$\begin{array}{l}\text { Means of transport to access } \\
\text { ANC services }\end{array}$} & Walk & 163 & $56 \%$ \\
\hline & Public transport & 90 & $30 \%$ \\
\hline & Private transport & 40 & $14 \%$ \\
\hline \multirow[t]{5}{*}{ Quality of ANC services } & Very poor & 2 & $1 \%$ \\
\hline & Poor & 4 & $2 \%$ \\
\hline & Average & 33 & $12 \%$ \\
\hline & Good & 218 & $70 \%$ \\
\hline & Very good & 36 & $15 \%$ \\
\hline
\end{tabular}

Table 2: Health Service Provider Factors Influencing ANC Utilization

\begin{tabular}{|c|c|}
\hline Variable & $\boldsymbol{\chi 2}$,df, P-value \\
\hline Where ANC services are accessed & $\chi 2=1.590 ; \mathrm{df}=4 ; \mathrm{P}=0.452$ \\
\hline Means of transport to access ANC services & $\chi 2=3.411 ; \mathrm{df}=4 ; \mathrm{P}=0.179$ \\
\hline $\begin{array}{c}\text { Quality of ANC services } \\
\mathrm{df}=6 ; \mathrm{P}=0.044^{*}\end{array}$ & $\chi 2=12.950 ;$ \\
\hline
\end{tabular}

Table 3: Association between Health Services Related Factors and ANC Utilization

\section{References}

i. African Population and Health Research Centre (APHRC). (2014). Population and Health Dynamics in Nairobi's Informal Settlements. Report of the Nairobi Cross-sectional Slums Survey (NCSS).

ii. Asweto, C. O., Aluoch, J. R., Obonyo, C. O., \& Ouma, J. O. (2014). Maternal Autonomy, Distance to Health Care Facility and ANC Attendance: Findings from Madiany Division of Siaya County, Kenya. American Journal of Public Health Research, 2(4), 153-158.

iii. Bayu, H., Adefris, M, Amano, A. \& Abuhay, M. (2015). Pregnant women's preference and factors associated with institutional delivery service utilization in Debr Markos Town, North West Ethiopia: a community-based follow up study. BMC Pregnancy and Childbirth, 15.

iv. Bhagwan, D., Kumar, A., Rao, C.R., \& Kamath, A. (2016). Utilization of antenatal care services in a rural field practice area in Coastal Part of South India. National Journal of Community Medicine, 7(4), 335-337.

v. Bustreo, F., Say, L., Koblinsky, M., Pullum, T.W., Temmerman, M., \& Pablos-Mendez, A. (2013). Ending preventable maternal deaths: the time is now. Lancet Global Health, 1(4), 176-7.

vi. Chorongo, D. (2016). Factors influencing the utilization of focused antenatal care services in Malindi and Magarini sub-counties of Kilifi County, Kenya. Pan African Medical Journal, 25(Suppl 2), 14.

vii. Fagbamigbe, A. F. \& Idemudia, E. S. (2015). Barriers to antenatal care use in Nigeria: evidences from non-users and implications for maternal health programming. BMC Pregnancy Childbirth, 15(1), 95.

viii. Gathuto, N. (2015). Factors influencing male participation in antenatal care in Kenya. BioMed Central. 
ix. Hagey, J., Rulisa, S. \& Perez-Escamilla, R. (2014). Barriers and solutions for timely initiation of antenatal care in Kigali, Rwanda: health facility professionals' perspective. Midwifery, 30(1):96-102.

x. Haver, J., Brieger, W., Zoungrana, J., Ansari, N. \& Kagoma, J. (2015). Experiences engaging community health workers to provide maternal and newborn health services: implementation of four programs. International Journal of Gynaecology and Obstetrics, 130 (Suppl 2), S32-39.

xi. Kawungezi, P.C., AkiiBua, D., Aleni, C., Chitayi, M., \& Tukei C. (2015). Attendance and utilization of antenatal care (ANC) services: Multi-center study in upcountry areas of Uganda. Open Journal of Preventive Medicine, 5(3), 13242.

xii. Kenya Demographic Health Survey (KDHS). (2016). Key Indicators. Nairobi: Kenya.

xiii. Kondwani, C. M., Adamson, S. M. \& Stone, W. (2017). Facility-imposed barriers to early utilization of focused antenatal care services in Mangochi District, Malawi - a mixed methods assessment. BMC Pregnancy and Childbirth, 17, 444.

xiv. Ministry of Health-Kenya. (2010). Kenya National Assembly Official Record (Hansard).

xv. Tsegay, Y., Gebrehiwot, T., \& Goicolea, I. (2013). Determinants of antenatal and delivery care utilization in Tigray region, Ethiopia: A cross-sectional study. International Journal of Equity Health, 12, 1-10

xvi. World Health Organization. (2014). Maternal mortality.

xvii. WHO (2014b). Trends in maternal mortality in 1990 to 2013: estimates by WHO, UNICEF, UNFPA, World Bank and United Nations population division. Geneva: World Health Organization. 